Research article

\title{
Nutritional composition and fungi deterioration of canned tomato products collected from Ibadan, South-western Nigeria
}

\author{
S. G. Jonathan ${ }^{1}$, B. J. Babalola ${ }^{1}$, O. J. Olawuyi ${ }^{2}$, J. A. Odebode ${ }^{3 *}$ and A. O. Ajayi ${ }^{4}$ \\ ${ }^{1}$ Mycology \& Biotechnology Unit, Department of Botany, University of Ibadan, Ibadan, Nigeria \\ ${ }^{2}$ Genetics and Molecular Biology, Department of Botany, University of Ibadan, Ibadan, Nigeria \\ ${ }^{3}$ Mycology Unit, Department of Botany, University of Lagos, Akoka Nigeria \\ ${ }^{4}$ Department of Microbiology, Federal University of Oye-Ekiti, Ekiti State, Nigeria
}

*Corresponding Author: odebode04@yahoo.co.uk

[Accepted: 11 December 2016]

\begin{abstract}
The present study was conducted in order to evaluate fungi and proximate analysis in three popularly consumed canned tomato products in Ibadan, Nigeria, Neurospora crassa was isolated from Pomo and Terra products while Aspergillus flavus and Macrophomina phaseolina was only isolated from Terra tin tomato products. The presence of Saccharomyces cerevisiae and Cercospora sp. was also observed in Pomo tin tomato products. Penicillium chrysogenum and Fusarium oxysporum was observed in Gino tin tomato products and Terra also shows the presence of $F$. oxysporum. The proximate analysis shows that the crude protein, ash content, ether extract and dry matter compositions of canned tomato products were significantly influenced by the brands of tomato product analyzed and it was indicted that the tomato products were very rich in nutrient. The Gino tin tomato presented the highest mean ash concentration with significant differences with respect to the Pomo and Terra tin products. There were no significant differences between the ether extract content when compared and significant differences were found within the replicates of the three tomato tin tomato products. The Gino tin products had the least mean value of crude protein which might be as a result of only two fungi isolates present while the high crude protein in Terra tin products is as a result more fungi contaminants that were present during isolation. The variations in aflatoxins levels in all the three mouldy tomato products indicates that they pose a threat to human health since there was invasion by toxigenic fungi after three weeks of storage. However, the opening of tin tomato products allows easy colonization of fungi and this has health implications on human being, Therefore, tin tomato products should be used immediately after opening.
\end{abstract}

Keywords: Proximate analysis - Tomato - Nutrient - Aflatoxins - Toxigenic fungi.

[Cite as: Jonathan SG, Babalola BJ, Olawuyi OJ, Odebode JA \& Ajayi AO (2016) Nutritional composition and fungi deterioration of canned tomato products collected from Ibadan, South-western Nigeria. Tropical Plant Research 3(3): 642-648]

\section{INTRODUCTION}

Tomato is a herbaceous plant (Solanum lycopersicum L.) and a member of the Solanaceae. It products are widely consumed by humans all over the world as processed products such as canned tomato, sauce, juice ketchup, stews and soup (Lenucci et al. 2006). Tomato products are essential source of vitamin A, vitamin C, potassium, fiber (Herson \& Hulland 1980, USDA 2012) and are considered as one of the most important ingredient in many dishes. It is desirable as dietary choices for vulnerable population groups such as the elderly (Banwart 1981, 2001, Buchann 2008) and it is associated with a reduced risk of chronic degenerable diseases (Agarwa \& Aai 2000, Rao \& Agarwal 1998). Tomato seeds contain high quality plant proteins that can be supplemented into various food products (Sogi et al. 2005). In recent years, tomato has received a considerable increment in its horizontal and vertical total annual production (FAO 1999).

In Nigeria, the demand for canned tomato products has increased considerably, because of its prevention of 
heart diseases and prostate cancer (Jones 2008) and in the lowering of high blood pressure and because of its fresh taste for salad. Tomatoes are now consumed world over. Tomatoes also contain calystegine alkaloids (polyhydroxylated nortropane alkaloids) (Asano et al. 1997, 2001). Tomato products make a significant contribution to human nutrition due to the concentration and availability of several nutrients in these products and to their widespread consumption (Sahlin et al. 2004). The processing of canned tomato paste seems to increase nutrient bioavailability, which could be due to the fact that the nutrients are detached or extracted from their structures. This is particularly true for lycopene (Rao et al. 1998, Shi \& Le 2000). Tomatoes and its byproducts serve as raw materials for several secondary products. A very valuable constituent of tomato is the red pigment carotenoid lycopene, an exceptionally efficient quencher of singlet oxygen and therefore an important anti-oxidant. Lycopene, as well as other valuable substances such as beta-carotene, alphacarotene, alpha-tocopherol, gamma-tocopherol and delta-tocopherol can be effectively extracted from tomato skins, seeds, and other by-products using supercritical fluid extraction technology (Baysal et al. 2000, Rozzi et al. 2002).

Canned tomato pastes are packed in tin or steel cans, an air-tight container for distribution, storage or preservation. Fungi may be found in canned tomato paste due to corrosion and leakage of the metals or from tin foils used in packaging. These canned containers have a high potential of harboring toxigenic fungi. In this study, the aim was to determine the nutritional analysis and the common fungi associated with the deterioration of canned tomato pastes

\section{MATERIALS AND METHODS}

Study area and sample collection

This study was conducted at the Mycology/pathology unit of the Department of Botany, University of Ibadan, Ibadan, Nigeria. Gino, Pomo and Terra, three popular brands of canned tomato products which are widely consumed among the University of Ibadan students were used in this research study and were purchased at Bodija markets in Ibadan, Nigeria. These samples were collected in sterile nylon and transported to the laboratory immediately.

\section{Sterilization of Materials and Media Preparation}

The canned tomato products were aseptically opened using a sterile tin cutter in a microbial free environment. The media used were sterilized at $121^{\circ} \mathrm{C}$ for 15 minutes in an autoclave and were prepared according to the manufacturers' instruction. Culture media generally used for the study is potato dextrose agar (PDA). All glass ware were sterilized in the hot air oven at $160^{\circ} \mathrm{C}$ for two hours. The inoculating needle were sterilized by flaming in the spirit lamp until red hot, working surface were sterilized by the application of sodium hypochlorite and absolute ethanol

\section{Isolation of pure cultures}

$5 \mathrm{ml}$ of the canned tomato products was measured into each of the sterilized McCartney bottles labeled accordingly. This was vigorously shaken and $1 \mathrm{ml}$ of sample was pipette into a sterile McCartney bottles containing $9 \mathrm{ml}$ of distilled water. The sample was serially diluted and $1 \mathrm{ml}$ each of aliquots of $10^{6}$ and $10^{7}$ were added to molten PDA plates. The plates were allowed to solidify and incubated at $30^{\circ} \mathrm{C}$ for $3-5$ days. The fungal colonies were counted every 24 hours. Successive hyphae tip were transferred until pure cultures of each of fungus was obtained. Pure culture were obtained by picking distinct colonies of fungi from the pour plate using inoculating needle and subculture into freshly prepared plates of PDA. The plates were incubated at room temperature. After which the pure culture was transferred into slant.

\section{Morphological and Microscopic Identification}

With the aid of the sterile inoculating needle, pure fungi isolates were inoculated into the centre of sterile potato dextrose agar plate to allow uniform growth distribution, hyphae formation with the colour and shape. A sterile inoculating needle was used to pick a thin films 48-72 hours old mycelium from a pure culture and was transferred to a drop of Lactophenol cotton blue in a clean, grease free glass slide and was gently teased in the stain to ensure mixing by using an inoculating needle. The slide was covered with a cove slip. Identification was done with the aid of microscope X10 and X40 objective lenses. The shape and arrangement of the fruity body was noted. This was done for the different isolates and the observations were recorded.

\section{Analysis of Nutrient Composition of Kilishi}

The crude protein, ether extract, ash content, and dry matter of the canned tomato products were determined 
according to AOAC (2005). The experimental plates were arranged in triplicates. Screening for aflatoxin B1 was also carried out using the procedure of AOAC Offical methods of analysis.

\section{Data analyses}

The data obtained were subjected to Analysis of Variance (ANOVA) using SPSS version 16.0. Duncan Multiple Range Test (DMRT) was further used to separate treatment means where there was significant difference. Tables, plates and graphs were also used to illustrate results as appropriate.

\section{RESULTS}

Different fungi were isolated from the various canned tomato products obtained from Bodija market, Ibadan. Neurospora crassa Shear \& B.O. Dodge was found in Pomo and Terra canned tomato products but was not present in Gino products. Aspergillus flavus Link and Macrophomina phaseolina (Tassi) Goid. was only isolated from terra canned tomato products. Saccharomyces cerevisiae Meyen ex E.C. Hansen and Cercospora sp. was also isolated from Pomo canned tomato products but was not found in Terra and Gino products. Penicillium chrysogenum Thom and Fusarium oxysporum Schlecht. emend. Snyder \& Hansen was observed in Gino tomato products (Table 1). Terra also shows the presence of Fusarium oxysporum but did not occur in

Table 1. Fungi isolated from canned tomato products purchased from Bodija market in Ibadan.

\begin{tabular}{llll}
\hline Fungi & Pomo & Terra & Gino \\
\hline Neurospora crassa Shear \& B.O. Dodge & + & + & - \\
Aspergillus flavus Link & - & + & - \\
Macrophomina phaseolina (Tassi) Goid. & - & + & - \\
Aspergillus terreus Thom & - & + & - \\
Saccharomyces cerevisiae Meyen ex E.C. Hansen & + & - & - \\
Penicillium chrysogenum Thom & - & - & + \\
Cercospora sp. & + & - & - \\
Fusarium oxysporum Schlecht. emend. Snyder \& Hansen & - & + & + \\
\hline
\end{tabular}

Note:,+ - indicates present and not present respectively.

Pomo products. The mean square effect of replicate, day after inoculation on the growth area of fungi found in POMO, TERRA and GINO Tomato Canned products in presented in table 2. The effect of replicate is nonsignificant for the growth area of the fungi isolated from Pomo and Terra tomato canned products but highly significant for the growth area of fungi found in Gino tomato canned products. The effect of day after inoculation is also significant for the growth area of the fungi found in Pomo tomato canned products but nonsignificant for the growth area of the fungi isolated from Gino tomato canned products but highly significant for the growth area of the fungi found in Terra Tomato canned products. The effect of replicates on the growth area of fungi found in POMO, TERRA and GINO Tomato Canned products is shown in table 3. Replicate 1 is significantly different from second replicate and third replicate. The least growth is of fungi isolated from Pomo products were found in third replicate.

Table 2. Effect of Mean Square of Replicate, Day after inoculation on the growth area of fungi found in POMO, TERRA and GINO Tomato Canned products.

\begin{tabular}{lllll}
\hline Source of variation & Df & GAP & GAT & GAG \\
\hline Rep & 2 & $19.27^{\text {ns }}$ & $4.50^{\text {ns }}$ & $10.20^{* *}$ \\
DAI & 4 & $19.74^{*}$ & $8.48^{* *}$ & $6.48^{\text {ns }}$ \\
Error & 38 & 6.72 & 3.00 & 5.77 \\
Total & 45 & & & \\
Corrected total & 44 & & & \\
\hline
\end{tabular}

Note: GAT = Growth area of fungi found in Terra, GAG= Growth area of fungi found in GINO.

$*=\mathrm{P}<0.01$ highly significant, $* *=\mathrm{P}<0.05$ significant, $\mathrm{ns}=$ Non-significant.

Table 3. Effect of Replicates on the growth area of fungi found in POMO, TERRA and GINO Tomato Canned products.

\begin{tabular}{llll}
\hline Replicate & GAP & GAT & GAG \\
\hline $\mathbf{1}$ & $6.79 \mathrm{a}$ & $7.35 \mathrm{a}$ & $4.69 \mathrm{~b}$ \\
$\mathbf{2}$ & $6.08 \mathrm{ab}$ & $8.06 \mathrm{a}$ & $3.28 \mathrm{~b}$ \\
$\mathbf{3}$ & $4.57 \mathrm{~b}$ & $6.98 \mathrm{a}$ & $7.19 \mathrm{a}$ \\
\hline
\end{tabular}

Note: GAP $=$ Growth area of fungi found in Pomo, GAT= Growth area of fungi found in Terra, GAG= Growth area of fungi found in GINO. Means with the same letter in the same column are not significantly different at $\mathrm{P}<$ 0.05 using Duncan's Multiple Range Test (DMRT).

www.tropicalplantresearch.com 
Table 4. Effect of Day After Inoculation on the growth area of fungi found in POMO, TERRA and GINO Tomato Canned products.

\begin{tabular}{llll}
\hline DAI & GAP & GAT & GAG \\
\hline $\mathbf{3}$ & $3.80 \mathrm{~b}$ & $4.89 \mathrm{c}$ & $3.89 \mathrm{a}$ \\
$\mathbf{6}$ & $4.75 \mathrm{ab}$ & $6.74 \mathrm{~b}$ & $4.72 \mathrm{a}$ \\
$\mathbf{9}$ & $6.30 \mathrm{ab}$ & $7.94 \mathrm{ab}$ & $4.97 \mathrm{a}$ \\
$\mathbf{1 2}$ & $7.03 \mathrm{a}$ & $8.87 \mathrm{a}$ & $5.53 \mathrm{a}$ \\
$\mathbf{1 5}$ & $7.18 \mathrm{a}$ & $8.87 \mathrm{a}$ & $6.14 \mathrm{a}$ \\
\hline
\end{tabular}

Note: DAI= Day ater inoculation, GAP=Growth area of fungi found in Pomo, GAT $=$ Growth area of fungi found in Terra, GAG= Growth area of fungi found in GINO Means with the same letter in the same column are not significantly different at $\mathrm{P}<0.05$ using Duncan's Multiple Range Test (DMRT).

There are non-significance differences exhibited by the replicate on the growth area of all the fungi isolated from Gino tomato canned products. However, third replicate is significantly different from first replicate and second replicate which are non-significantly different from each other for the growth area of fungi isolated from Gino Tomato Canned products. The Effect of Day after inoculation on the growth area of fungi isolated in POMO, TERRA and GINO Tomato Canned products is shown in table 4. There is non-significance differences between the growth area of the fungi isolated from Pomo tomato canned products at 12 and 15 DAI, but significantly different from 6 and 9 DAI which are non-significantly different from each other. The growth are of fungi found in Pomo products at 3DAI is significantly different with the least mean value of 3.80. Also, the growth area of the fungi isolated from terra at 12 and 15 DAI are non-significantly different from each other but significantly different from 3, 6 and 9 DAI which are significantly different from each other. There are non-

Table 5. Mean square table of Tomato product showing the proximate analysis.

\begin{tabular}{llllll}
\hline Source & df & CP $(\%)$ & AS $(\%)$ & EE $(\%)$ & DM (\%) \\
\hline Tomato & 2 & $57.26^{* *}$ & $22.71^{* *}$ & $0.00^{\mathrm{ns}}$ & $0.00^{\mathrm{ns}}$ \\
Rep & 2 & $2.95^{\mathrm{ns}}$ & $6.02^{* *}$ & $0.05^{* *}$ & $1676.30^{* *}$ \\
Error & 4 & 4.77 & 0.18 & 6.11 & 1.88 \\
Total & 9 & & & & \\
Corrected total & 8 & & & & \\
\hline Note: $\mathrm{CP}=$ Crude protein, $\mathrm{AS}=\mathrm{Ash}, \mathrm{EE}=$ Ether extract, $\mathrm{DM}=$ Dry matter. \\
$*=\mathrm{P}<0.01$ highly significant, $* *=\mathrm{P}<0.05$ significant, $\mathrm{ns}=$ Non-significant.
\end{tabular}

significant differences between all the growth areas of the fungi isolated from Gino for all the days after inoculation. The mean square effect shows that the Crude protein, Ash content were highly significant for the tomato products but Ether extract, and dry moisture were non-significant for the tomato paste products. The mean effect on the replicate also shows that it is highly significant for ash content, ether extract and dry moisture but non-significant for crude protein (Table 5).

Table 6. Effect of Tomato Canned products on the proximate analysis.

\begin{tabular}{lllll}
\hline Tomato products & CP $(\boldsymbol{\%})$ & AS (\%) & EE (\%) & DM (\%) \\
\hline Gino & $3.11 \mathrm{c}$ & $9.50 \mathrm{a}$ & $0.86 \mathrm{a}$ & $49.99 \mathrm{a}$ \\
Pomo & $5.26 \mathrm{~b}$ & $7.08 \mathrm{~b}$ & $0.87 \mathrm{a}$ & $50.00 \mathrm{a}$ \\
Terra & $11.52 \mathrm{a}$ & $4.01 \mathrm{c}$ & $0.88 \mathrm{a}$ & $50.00 \mathrm{a}$ \\
\hline
\end{tabular}

Note: $\mathrm{CP}=$ Crude protein, $\mathrm{AS}=\mathrm{Ash}, \mathrm{EE}=$ Ether extract, $\mathrm{DM}=$ Dry matter.

$*=\mathrm{P}<0.01$ highly significant, $* *=\mathrm{P}<0.05$ significant, $\mathrm{ns}=$ Non-significant.

Table 6 shows the effect of tomato products on the proximate analysis. The Gino tomato product shows the least mean value for $\mathrm{CP}$ and it is significantly different from the $\mathrm{CP}$ of POMO and TERRA. The highest mean value for crude protein was shown in Terra. There is a significant difference among the ash content of Gino, Pomo and Terra Tomato products. The least ash content was obtained from terra. For the ether extract and moisture content, there were non-significant differences between Gino, Pomo and Terra. Table 7 shows the

Table 7. Effect of replicate on the proximate analysis of tomato products.

\begin{tabular}{lllll}
\hline Replicate & $\mathbf{C P}(\boldsymbol{\%})$ & $\mathbf{A S}(\boldsymbol{\%})$ & $\mathbf{E E ~ ( \% )}$ & DM (\%) \\
\hline $\mathbf{1}$ & $7.67 \mathrm{a}$ & $8.33 \mathrm{a}$ & $1.00 \mathrm{a}$ & $26.36 \mathrm{bc}$ \\
$\mathbf{2}$ & $6.54 \mathrm{ab}$ & $5.51 \mathrm{c}$ & $0.74 \mathrm{c}$ & $73.63 \mathrm{a}$ \\
$\mathbf{3}$ & $5.69 \mathrm{~b}$ & $6.75 \mathrm{~b}$ & $0.87 \mathrm{~b}$ & $50.00 \mathrm{~b}$ \\
\hline
\end{tabular}

Note: $\mathrm{CP}=$ Crude protein, $\mathrm{AS}=\mathrm{Ash}, \mathrm{EE}=$ Ether extract, $\mathrm{DM}=$ Dry matter. $*=\mathrm{P}<0.01$ highly significant, $* *=\mathrm{P}<0.05$ significant, $\mathrm{ns}=$ Non-significant. 
effect of replicate on the proximate analysis of tomato products. First replicate has the highest crude protein and its significantly different from second replicate, third replicate has the least protein value of 5.69. For Ash content, Replicate 1 is significantly different from second replicate and third replicate while second replicate shows the least value for the ash content 5.51. The ether extract of first replicate is also significantly different from second replicate and third replicate, second replicate shows the least value of 0.74 . The effect of second replicate on dry weight is significantly different from first and third replicates. First replicate has the least mean value of 26.36. Figure 1 shows the presence of aflatoxin B1 in a mouldy kilishi.

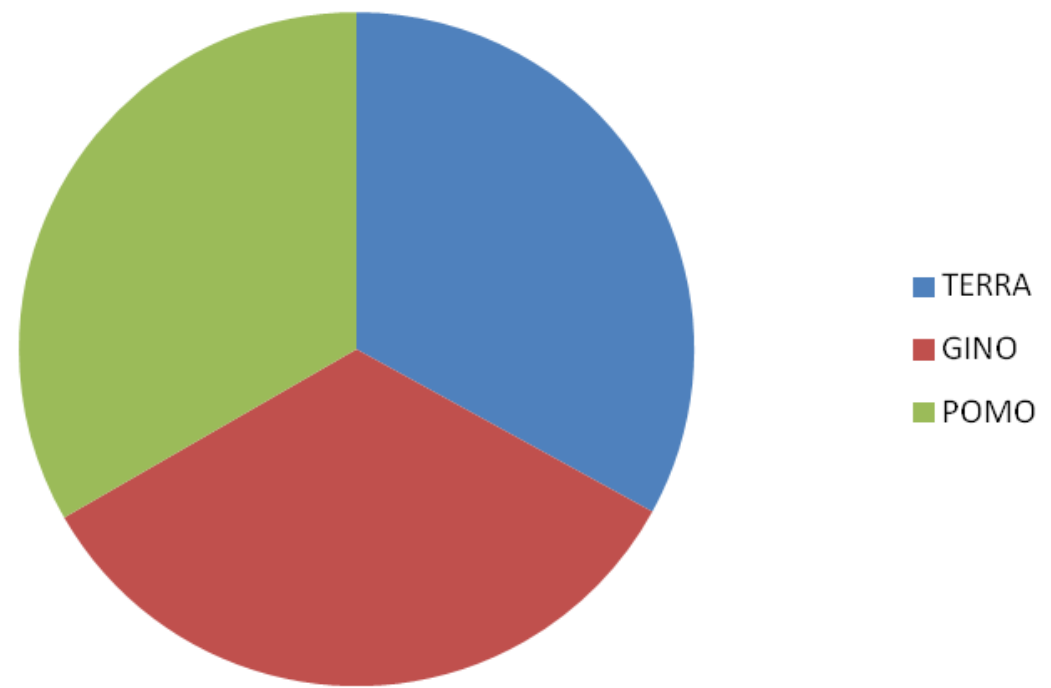

Figure 1. Aflatoxin B1(ug/kg) Assay in Mouldy Tomato Canned products.

\section{DISCUSSION AND CONCLUSION}

The analysis carried out showed that various fungi can be isolated from canned tomato products. This study agrees with the work of Kalyoncu et al. (2005) who reported the presence of Aspergillus flavus, A. terreus Thom, Fusarium oxysporum, Penicillium ochraceus in home-made tomato paste samples from the fields and markets in Manisa Province of Turkey. High rate of fungi found in Pomo and Terra canned tomato products could be as a result of leakage in the packaging tin can. There might be two factors such as packaging and processing method that influence growth of fungi and the proximate composition of tomatoes. The result of this study is in accordance with the report made by Alabi \& Esan (2013) who identified Aspergillus flavus, A. fumigatus Fresenius, A. niger van Tieghem and Fusarium sp. associated with the spoilage of the industrial tomato paste. The processing method is a more influential factor than production method. Some differences in the ripening stage could decisively influence the studied proximate parameters. The aflatoxins detected in all the three mouldy tomato products indicates that they pose a threat to human health since there was invasion by toxigenic fungi after three weeks of storage. Microorganisms isolated from the tin tomato products are in accordance with previous report where enzymes of A. flavus and A. fumigatus were found to be responsible for the deterioration of tomato fruit (Adisa 1985). Aspergillus sp. is very common and is involved in spoilage of food items. This work is also in line with the work of Kolawole et al. (2010) who reported the presence of Aspergillus sp., Aspergillus niger, Rhizopus stolonifer (Ehrenb.: Fr.) Vuill. and Penicillium chrysogenum in dried tomato products. The health status of man can be compromised with aspergillosis if after large amounts of spores are inhaled. ANOVA reveals that the tomato pastes were very rich in nutrient and can easily out rank all other vegetables in total contribution to human nutrition (Grubben \& Denton 2004). The proximate analysis showed that the crude protein, ash content, ether extract and dry matter compositions of tomato fruits were significantly influenced by the brands of tomato product analysed. The Gino tin tomato presented the highest mean ash concentration with significant differences with respect to the Pomo and Terra tin products. The high ash content obtained in Gino tomato products might be due to the phosphorus fertilizer supplementation that acted on the tomato fruit on the field (Oke et al. 2005). However, there were no significant differences between the ether extract content when compared and significant differences were found within the replicates of the three tomato tin tomato products. The mean content of total crude protein in the analyzed Terra tin tomatoes was 11.52 which were significantly higher than other Gino tomato products. The GINO tin products had the least mean value of crude protein (3.11) possibly as a result of the low level of fungi present www.tropicalplantresearch.com 
(fungi isolates from Gino were Penicillium chrysogenum and Fusarium oxysporum) while the high crude protein in Terra tin products is as a result more fungi contaminants (Cotran et al. 1999, Diane 2004). Atteh (2002) reported a similar increase in the level of crude protein and ash of dried tomato. The result of the proximate analysis showed that, there was significant difference $(p<0.05)$ in the dry matter at replicate level of the tomato tin product. The dry matter content of the tomato tin product ranged from 49.99-50.00 for Gino, Pomo and Terra respectively.

\section{ACKNOWLEDGEMENTS}

Special thanks to Department of Botany, University of Ibadan for access to the laboratory. There is no conflict of interest whatsoever.

\section{REFERENCES}

Adisa VA (1985) Effects of the biodeterioration caused by two molds on some food substances of Ananas comosus. Phytoparasitica 13(2):113-120.

Agarwa A \& Rao AV (2000) Tomato lycopene and its role in human health and chronic diseases. Canadian Medical Association Journal 163: 739-744.

Alabi OA \& Esan BE (2013) Comparative studies on the relative biopreservative efficiencies of major tropical vegetable oils on industrial tomato (lycopersicum esculentum) paste in storage Journal of Natural Product and Plant Resource 3: 7-11.

AOAC (2005) Official Method of Analysis, $14^{\text {th }}$ Edition. Association of Official Analytical Chemist, Washington. DC.

Asano N Kato A Matsui K Watson AA Nash RJ Molyneux RJ Hackett L Topping J \& Winchester B (1997) The effects of calystegines isolated from edible fruits and vegetables on mammalian liver glycosidases. Glycobiology 7: 1085-1088.

Asano N, Yokohama K, Sakurai M, Ikeda K, Kizu H, Kato A, Arisawa M, Hoke D, Drager B, Watson AA \& Nash RJ (2001) Dihydroxynotropane alkaloids from calystegine-producing plants. Phytochemistry 57: 721726.

Atteh JO (2002) Feed ingredient their composition and idiosyncrasies, principles and practice of livestock feed Manufacturing. Journal of Agricultural Science 2: 212-224.

Banwart GJ (1981) Basic Food Microbiology. Westport Connecticut: The AVI publishing company Inc. Westpoint.

Banwart GJ (2001) Bacteria as food spoilage organisms. Basic food microbiology. Avi Publishing Co. Westport. Conn., pp. 119-125.

Baysal T, Ersus S \& Starmans DA (2000) Supercritical Fluid Extraction of beta-carotene and lycopene from tomato paste waste. Journal of Agriculture and Food Chemistry 48: 5507-5511.

Buchann GJ (2008) Basic Food Microbiology. AVI publishing company, Westport.

Cotran RS, Vinay K \& Tucker C (1999) Infectious disease. Robins pathologic basis of disease 6th edition. W.B. Sanders Company, pp 380-381.

Diane AC (2004) Bacterial disease of Tomatoes. Agriculture Agric-food Canada, London Ontario.

FAO (1999) Year book of Production. Rome, Italy, volume 35, pp. 36-59.

Grubben GHJ \& Denton (2004) Plant Resources of Tropical Africa 2: Vegetables. PROTA Foundation/Back hugs Publishers/CTA. Wageningen, Netherland, pp 522-526.

Herson AC \& Hulland ED (1980) Canned Foods: Thermal Processing and Microbiology. Edinburgh: Churchill Livingstone.

Jones BJ (2008) Tomato plant culture in the field, Greenhouse and Home Garden. $2^{\text {nd }}$ eds. CRC Press Taylor \& Francis Group. Boca Ranton, USA, pp. 75-77.

Kayyoncu F, Tamer AU \& Oskay M (2005) Determination of fungi associated with Tomatoes (Lyscopersicum esculentum M.) and tomato pastes. Plant Pathology Journal 4(2): 146-149.

Kolawole OM, Kayode RMO \& Aina J (2010) The Drying Effect of Varying Light Frequencies on the Proximate and Microbial Composition of Tomato. Journal of Agricultural Science 2: 212-224.

Lenucci MS, Cadinu D, Taurino M, Piro G \& Dalessandro G (2006) Antioxidant composition in cherry and high-pigment tomato cultivars. Journal of Agriculture and Food Chemistry 54: 2606-2613.

Oke M, Ahn T, Schofield A \& Paliyath G (2005) Effects of phosphorus fertilizer supplementation on processing www.tropicalplantresearch.com 
quality and functional food ingredients in tomato. Journal of Agricultural and Food Chemistry 53: 15311538.

Rao AV \& Agarwal S (1998) Bioavailability and in vivo antioxidant properties of lycopene from tomato products and their possible role in the prevention of cancer. Nutrition and Cancer 31: 199-203.

Rozzi NL, Singh RK, Vierling RA \& Watkins BA (2002) Supercritical fluid extraction of lyopene from tomato processing byproducts. Journal of Agriculture and Food Chemistry 50: 2638-2643.

Sahlin GP, Savage C \& Lister E (2004) Investigation of the antioxidant properties of tomatoes after processing. Journal of Food Composition and Analysis 17: 635-647.

Shi J \& Le MM (2000) Lycopene in tomatoes: Chemical and Physical Properties affected by food processing. Review in Food Science and Nutrition 40: 1-42.

Sogi DS, Bhatia R, Garg SK \& Bawa AS (2005) Biological evaluation of tomato waste seed meals and protein concentrate. Food Chemistry 89: 53-56.

USDA (2012) Nutrition Facts: Tomatoes, red, ripe, raw, year round average. Available from: http://nutritiondata.self.com/facts/vegetables-andvegetable- (accessesd: 22 Oct. 2012). 